\title{
A review of the genus Mecistorhabdia (Lepidoptera: Erebidae: Arctiinae: Syntomini) with a description of a new species from the Central African Republic
}

\author{
NikolaI IGNATEV ${ }^{1,2}$, BeATA GRZYWACZ ${ }^{3}$ and ŁuKASZ PRZYBYŁOWICZ ${ }^{3}$ \\ ${ }^{1}$ Institute of Entomology, Biology Centre CAS, Branisovska 31, 37005 Ceske Budejovice, Czech Republic, and Faculty of \\ Sciences, University of South Bohemia, Ceske Budejovice, Czech Republic; e-mail: n.ignatev@entu.cas.cz \\ ${ }^{2}$ Museum Witt, Tengstraße 33, 80796 Munich, Germany \\ ${ }^{3}$ Institute of Systematics and Evolution of Animals, Polish Academy of Sciences, Sławkowska 17, 31-016 Krakow, Poland; \\ e-mails: grzywacz@isez.pan.krakow.pl, lukasz@isez.pan.krakow.pl
}

Key words. Lepidoptera, Erebidae, Arctiinae, Syntomini, Mecistorhabdia, new species, Afrotropical region, systematics, COI

\begin{abstract}
The genus Mecistorhabdia Kiriakoff, 1953 is reviewed and one new species M. sulaki sp. n. from the Central African Republic and Cameroon (Afrotropical region) described. The holotype female of the type species M. haematoessa (Holland, 1893) is matched with a conspecific male using a molecular technique. M. burgessi Kiriakoff, 1957 is removed from the synonymy as it is considered to be a valid species. Habitus and male genitalia of all three species are illustrated along with the female genitalia of $M$. haematoessa. A key for identification of species based on the structure of male genitalia and a map of their distribution are provided. The results of a study of the genetic diversity of the three species of Mecistorhabdia, based on cytochrome $c$ oxidase subunit I gene, are presented. Relationships between species are briefly discussed.
\end{abstract}

ZooBank Article Registration: http://zoobank.org/urn:Isid:zoobank.org:pub:350BED21-ED91-4276-90E9-8AF1D2B2CCBC

\section{INTRODUCTION}

For a long time the thyretines were thought to be a separate monophyletic lineage and treated as a separate family, the Thyretidae (Kiriakoff, 1949). Following morphological and molecular studies of the entire Noctuoidea it was downgraded to tribal rank by Jacobson \& Weller (2002) and finally treated as a subtribe Thyretina of Syntomini (Zahiri et al., 2011). Recently a comprehensive molecular study revealed that the Thyretina is not monophyletic (Przybyłowicz et al., 2019). As a result, it was formally synonymized with Syntomini. The group was revised by Przybyłowicz (2009), but since then very few papers have been published. Among these, Durante \& Potenza (2014) listed the species of the genus Balacra Hampson, 1914 recorded in Gabon and Durante \& Zangrilli (2016) revised the subgenus Daphaenisca Kiriakoff, 1953 and described three new species.

Until recently the genus Mecistorhabdia included only a single valid species, $M$. haematoess $a$, which was originally placed by Holland (1893) in the genus Metarctia Walker, 1855. This species was described based on a single female without description of its reproductive organs. Kiriakoff (1953) revised the status of this taxon and proposed a new genus Mecistorhabdia. The diagnosis of the new genus was based on significant differences in the newly described male genitalia in comparison with the genus Elsa (now Rhipidarctia Kiriakoff, 1953) with which Mecistorhabdia was compared in the original description. He provided the description of male genitalia supplemented by rather schematic drawings, but did not describe the female genitalia. Later Kiriakoff (1957) described one additional species, $M$. burgessi, from Uganda based on a single male. This new taxon was subsequently synonymized with $M$. haematoessa by Przybyłowicz \& Kühne (2008). These authors wrongly treated the small differences in colouration and male genitalia structures as intraspecific variability. The same misinterpretation was repeated by Przybyłowicz (2009) in his catalogue of Thyretini.

The study of type specimens of both taxa and additional material from adjacent territories has made it possible to study this genus in more detail and as a consequence to describe another new taxon. Using molecular techniques, we managed to associate correctly the female holotype of M. haematoessa with known males and prove the morphological distinctiveness of taxa by using molecular and morphological approach. We verify the distribution of species 
and provide high-quality illustrations of the reproductive organs enabling an easier separation of species.

\section{MATERIALS AND METHODS}

In this study we follow the systematic account of Przybyłowicz et al. (2019) for the higher taxonomic levels.

Specimens of the genus Mecistorhabdia were collected in Uganda (July 2011 by Harald Sulak), Central African Republic (September 2000 by local collector) and Republic of the Congo (January to March 1997 by Viktor Siniaev and Vladimir Murzin) and stored in the MWM collection. Additional material from the RMCA and ISEAPAS collections was used for comparison.

The abdomens were removed and placed in cold $5 \% \mathrm{KOH}$ solution overnight after which the abdominal cuticle was opened by a right lateral cut to the genitalia, which were removed and stained in Evans Blue. The aedeagus was pulled out caudally. Images of genitalia were taken using a Leica DFC450 camera.

Forewing length was measured from the base to the apex of the wings, parallel to the wing costa. Forewing width was measured perpendicularly from the costa to the tornus.

Morphological terms for genitalia are those used by Klots (1970).

Abbreviations: FW - forewing; GP - genitalia slide; HW hindwing; CMNH - Carnegie Museum of Natural History, Pittsburgh, USA; ISEAPAS - Institute of Systematics and Evolution of Animals, Polish Academy of Sciences, Kraków, Poland; MWM - Museum Witt, Munich, Germany; NECUJ - Nature Education Centre of Jagiellonian University, Kraków, Poland; NHMUK Natural History Museum, London, UK; RBINS - Royal Belgian Institute of Natural Sciences, Brussels, Belgium; RMCA - Royal Museum for Central Africa, Tervuren, Belgium; ZSM - Zoologische Staatssammlung des Bayerischen Staates, Munich, Germany.

\section{Molecular analysis}

Total genomic DNA was extracted from leg muscle tissue of dried specimens or specimens preserved in pure ethanol using the GeneMATRIX Bio-Trace DNA Purification kit (EURx, Poland, following the standard protocol for tissue). The cytochrome c oxidase subunit I gene (COI) was amplified by polymerase chain reaction (PCR) using the primers LCO1490 (5'-GGT CAA CAA ATC ATA AAG ATA TTG G-3') and HCO2198 (5'-TAA ACT TCA GGG TGA CCA AAA AAT CA-3') (Folmer et al., 1994). In case of failure in sequencing with these primers, additional PCR reactions were carried out to recover amplicons using primers ZBJ-ArtF1c (5'-AGA TAT TGG AAC WTT ATA TTT TAT TTT TGG-3') and ZBJ-ArtR2c (5'-WAC TAA TCA ATT WCC AAA TCC TCC-3') (Zeale et al., 2011). This combination was neces- sary with the old female holotype of $M$. haematoessa (specimen No. 18.4.6), which is more than 100 years older than the other material. If one of these reactions was successful, an effort was made to obtain a barcode compliant record ( $>650 \mathrm{bp}$ ) by amplifying shorter regions of COI. PCR were performed in $25 \mu 1$ reaction volume using $2 \times$ Phanta Max Master Mix (Vazyme Biotech Co., Ltd, China), $10 \mathrm{mM}$ dNTP Mix, $10 \mu \mathrm{M}$ of each primer and $4 \mu \mathrm{l}$ of the genomic DNA. The PCR profile consisted of an initial denaturation step at $94^{\circ} \mathrm{C}$ for 3 min, followed by 36 cycles at $94^{\circ} \mathrm{C}$ for $1 \mathrm{~min}, 48^{\circ} \mathrm{C}$ for $1 \mathrm{~min}$, and $72^{\circ} \mathrm{C}$ for $2 \mathrm{~min}$ and a final extension step of $7 \mathrm{~min}$ at $72^{\circ} \mathrm{C}$. Successful PCR products were purified using the GeneMATRIX PCR/DNA Clean-Up Purification kit (EURx, Poland, following the standard protocol) and sequenced in both directions. All sequences were deposited in GenBank under the accession numbers MN441758 and MN441760MN441768 (Table 1). The sequence of Mecistorhabdia burgessi from the GenBank database was also included in the analysis (Accession Number MK158553). Arctia caja (Linnaeus, 1758) and Lithosia quadra (Linnaeus, 1758) in the tribe Arctiini and Lithosiini, respectively (both in subfamily Arctiinae), were chosen as outgroup for analysis and the sequences were also taken from the GenBank database (Accession Numbers: HM873709 and KJ547685, respectively).

The obtained nucleotide sequences were edited and assembled into contigs in CodonCode Aligner (CodonCode Corporation). Sequences were also checked for protein-coding frame shifts to detect pseudogenes using MEGA X (Kumar et al., 2018) and compared with sequences from GenBank using a BLAST search. Best-fit models for Bayesian (BI) and maximum likelihood (ML) analyses were calculated in MrModeltest (Nylander, 2004) using the Akaike information criterion (AIC). ML analyses were carried out in IQTree (Nguyen et al., 2015). Bootstrap support was calculated using 1000 replicates. BI analyses were performed in MrBayes (Ronquist \& Huelsenbeck, 2003) with four independent runs, each having three heated and one cold chain. Analyses were run for 6 million generations with trees sampled every 1000 generations. The first $25 \%$ of each run was discarded as burn-in. Convergence among the runs was assessed using Tracer (Rambaut et al., 2018). All trees were visualized using FigTree with a midpoint rooting option (Rambaut \& Drummond, 2012).

Pairwise sequence divergences were calculated separately for intraspecific as well as interspecific comparisons with MEGA X using Kimura's two parameter (K2P) distance model. Species delimitation method Automatic Barcode Gap Discovery, ABGD (Puillandre et al., 2012), is an automatic procedure that considers the sequences as hypothetical species based on the barcoding gap. The model first calculates a range of prior intraspecific diver-

Table 1. Taxonomic information and GenBank $\mathrm{COI}$ accession numbers of the taxa included in this study. $\left(^{*}\right)$ indicates the female holotype of $M$. haematoessa.

\begin{tabular}{lcccc}
\hline Species & Specimen & Origin & GenBank COI Acc. No. & References \\
\hline & 18.4 .1 & Africa: Angola, Cuanza Prov. & MN441768 & This study \\
Mecistorhabdia & 18.4 .2 & Africa: Cameroon, Mt. Cameroon & MN441764 & This study \\
haematoessa & 18.4 .3 & Africa: Cameroon, Mt. Cameroon & MN441763 & This study \\
& 18.4 .4 & Africa: Cameroon, Mt. Cameroon & MN441765 & This study \\
& 18.4 .5 & Africa: Cameroon, Mt. Cameroon & MN441766 & This study \\
& $18.4 .6\left(^{*}\right)$ & Africa: Gabon, Ogooué River & MN441767 & This study \\
\hline \multirow{4}{*}{ Mecistorhabdia burgessi } & LN051 & Africa: Uganda, Kibale NP & MK158553 & Przybylowicz et al., 2019 \\
& C10_II & Africa: DR Congo, Salonga NP & MN44441762 & This study \\
\hline Mecistorhabdia sulaki & B10_I & Africa: Uganda, Kibale NP & MN441761 & This study \\
\hline Arctia caja & 22.5 & Africa: Uganda, Kibale NP & MN441760 & This study \\
\hline Lithosia quadra & aca & Africa: Cameroon, Ebogo & MN441758 & This study \\
\hline
\end{tabular}




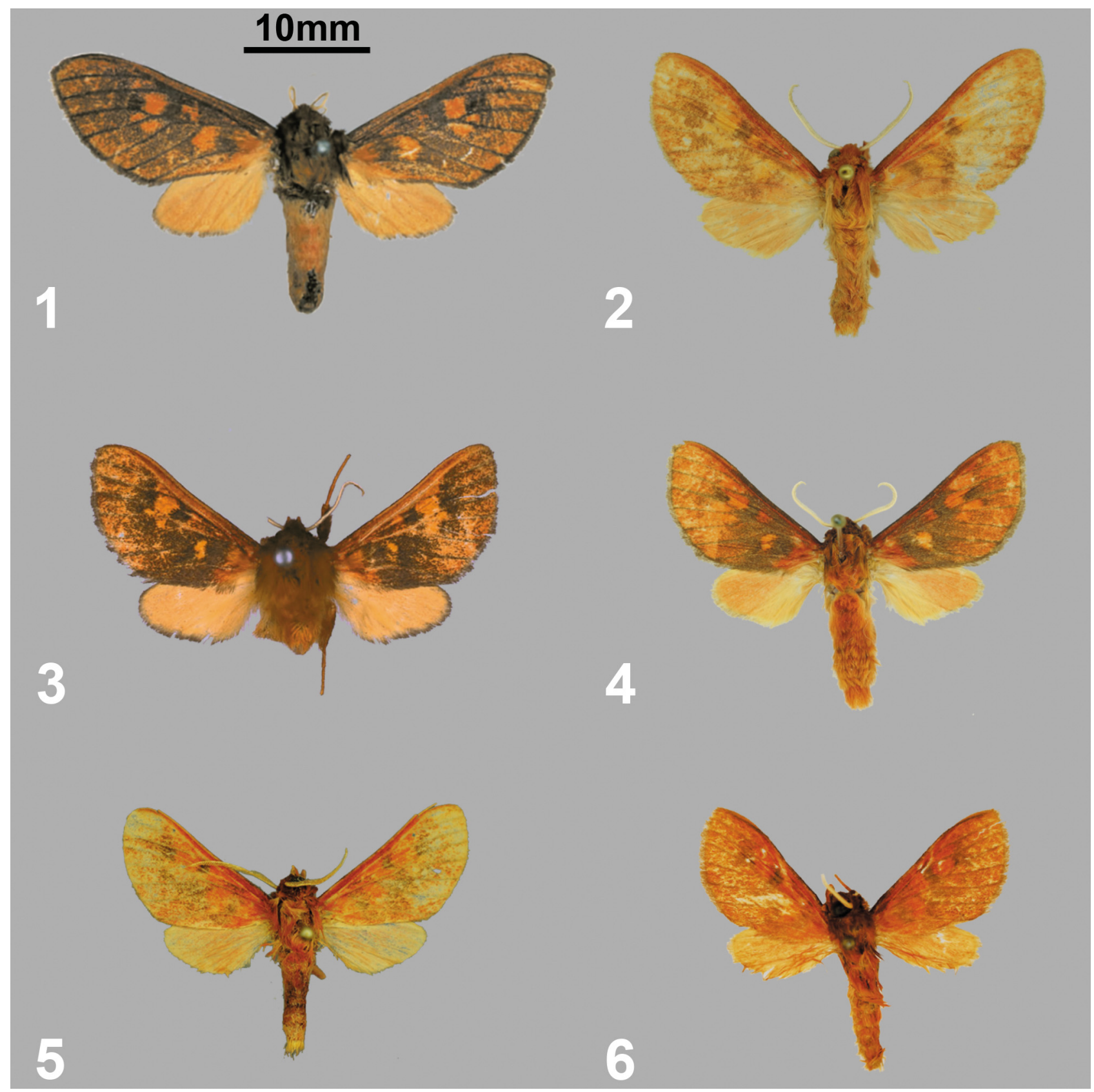

Figs 1-6. Adults of Mecistorhabdia spp. 1 - holotype female of $M$. haematoessa; 2 - male of $M$. haematoessa; 3 - holotype male of $M$. burgessi; 4 - male of $M$. burgessi; 5 - holotype male of $M$. sulaki sp. n.; 6 - paratype male of $M$. sulaki sp. n.

gence to obtain the maximum limit of the intraspecific diversity and then partitions the data on the basis of the first significant gap beyond this limit, which is a potential limit between intra- and interspecific diversity. The data set was submitted to the ABGD online website (https://wwwabi.snv.jussieu.fr/public/abgd/) and analysed using the following settings: $\mathrm{P}$ (prior intraspecific divergence) set from 0.001 (Pmin) to 0.08 (Pmax) and Steps set to 10; $\mathrm{X}$ (minimum relative gap width) set to $1 ; \mathrm{Nb}$ bins (for distance distribution) set to 20 and Kimura (K80) model and TS/TV set to 2.0 were selected.

\section{RESULTS}

\section{Genus Mecistorhabdia Kiriakoff, 1953}

Kiriakoff, 1953: 29; Przybyłowicz, 2009: 16, 56.

Type species: Metarctia haematoessa Holland, 1893: 396 (original designation).

\section{Mecistorhabdia haematoessa (Holland, 1893)}

(Figs 1, 2, 7, 8, 9, 12, 13, 15)

Metarctia haematoessa Holland, 1893: 396.

Mecistorhabdia haematoessa (Holland, 1893): Kiriakoff, 1953: 29; 1957: 97; Przybyłowicz \& Kühne, 2008: 150; Przybyłowicz, 2009: 56.

Diagnosis. Habitus is quite similar to M. burgessi but distinctly differs from it in the male having a larger wingspan $-30-35 \mathrm{~mm}$ and $28-30 \mathrm{~mm}$ respectively. The structure of male genitalia should be used for safe identification, so in contrast to $M$. burgessi costal process of valva C-curved, the length of saccular process of valva is longer or equal in length to costal process. Vesica bears minute but distinct cornutus. It is also noteworthy that the coloura- 


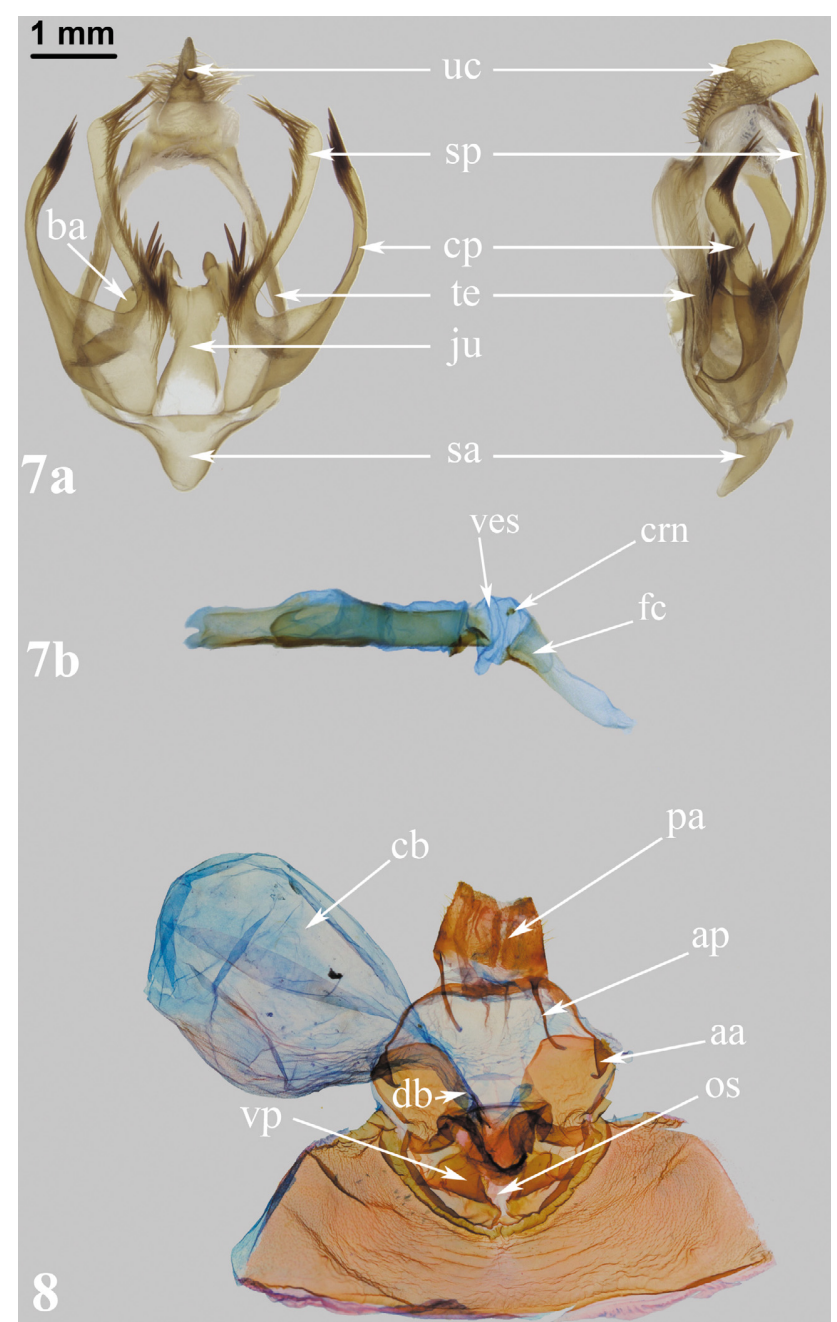

Figs 7-8. Structures of the male and female genitalia of Mecistorhabdia haematoessa. $7 \mathrm{a}$ - male genitalia ventral view (left) and dorsal lateral view (right): uc - uncus; ba - basal appendage of valva; $\mathrm{sp}$ - saccular process; $\mathrm{cp}$ - costal process; te - tegumen; ju - juxta; sa - saccus. $7 \mathrm{~b}$ - aedeagus: ves - vesica; crn - cornutus $\mathrm{fc}-$ field of tiny cornutti. 8 - female genitalia: $\mathrm{cb}$ - corpus bursae; pa - pappilae anales; ap - apophyses posteriors; aa - apophyses anteriores; $\mathrm{db}$ - ductus bursae; os - ostium; vp - vaginal plate.

tion of M. haematoessa is much less orange than that of $M$. burgessi.

Male (Fig. 2). Wingspan: 30-35 mm; FW length: 18 mm, width: $8 \mathrm{~mm}$, ratio $2.3: 1$; HW length: $11 \mathrm{~mm}$, width: $7 \mathrm{~mm}$, ratio $1.6: 1$. Antenna bipectinate, bright yellow. Head and patagia pale brown, tegula, thorax covered by dirty orange and yellow elongate scales. Abdomen dorsally light orange, ventrally pale brown. Forewing pale orange grey, with pale orange costal margin and blurs of dark yellow scales on postbasal, discal, postdiscal areas. Marginal edge of forewing mainly yellow. Hindwing pale-yellow.

Female (Fig. 1). Wingspan: 40-45 mm; FW length: 25 $\mathrm{mm}$, width: $12 \mathrm{~mm}$, ratio $2.1 \mathrm{:}$; HW length: $11 \mathrm{~mm}$, width: $9 \mathrm{~mm}$, ratio $1.2: 1$. Antenna bipectinate, yellow. Head, patagia and thorax covered with elongate grey scales. Abdomen dorsally dirty orange. Forewing grey with inclusions of dirty orange scales on costal margin and discal area; basal area bears two distinct dirty orange spots, post basal area has three dirty orange spots. Marginal edge of forewing mainly grey. Hindwing dark yellow.

Male genitalia (Figs 7, 9). Uncus coracoid shaped, extended in medial part; dorsally and laterally covered by elongate setae. Tegumen ribbon-shaped. Valvae symmetrical, divided in to two elongated and slightly curved processes: saccular process, which are the same length or longer than the costal process, covered by setae abdominally; costal process narrows towards top, dorsal edge and tip covered by elongate setae. At the base valvae bear basal appendage, which is almost half the size of costal process, curved dorsally and tip well covered with sclerotized elongate setae. Juxta well developed, almost X-shaped. Saccus rounded at top. Aedeagus tubular, narrows in basal part. Vesica divided in to two lobes - elongate dorsal with field of small sclerotizations on the base and an abdominal one with one or two small cornuti.

Female genitalia (Fig. 8). Papillae anales rounded and covered with setae; apophyses posteriors well developed; VIII segment strongly connected with vaginal plate, which is well developed and forms two bumps on the side of ostium; apophyses anteriores very small, almost three times shorter than apophyses posterior; corpus bursae oviform shape; ductus bursae, ductus seminalis and corpus bursae not sclerotized, without signum.

Type material examined. Holotype $\circ$, Gabon, Valley of the Ogooué River, Kangwé, leg. A.C. Good (Africa) [CMNH] (genitalia rotten).

Other material examined. Cameroon. $5 \hat{\partial}$, Mt Cameroon, SW slope, Elephant Camp, 1850 m, N 4.1453330 E 9.0870000, 2017-02-17, leg. P. Potocky, R. Tropek, J. Mertens, S. Janecek [NECUJ]; $1{ }^{\AA}$, Mt Cameroon, SW slope, Planty Camp, 1100 m, N 4.1175000 E 9.0709440, 2016-01-29, leg. V. Maicher, Sz. Safian, S. Janecek, R. Tropek, [NECUJ]; $1 \hat{\delta}$ as above but 2016-01-31; $1 \hat{\delta}$ as above but 2016-02-03. $1 \hat{\delta}$, Rte. Edea-Douala 12-1991, Th. Bouyer, NI GP 0.006 [RMCA]. 1ठð, Mann's Spring 13.02.1989, $1800 \mathrm{~m}$, trap on Dr Edwards, tree plot. Montane forest dom, trees Schefflera Nuxia ground vegetation Piper. NI GP 0.007 [RMCA]. $1 \hat{\jmath}$, as above but NI GP 0.008 [RMCA]. $1 \hat{\jmath}$, Zamakoë res. For. 4/5-7-1992, Th. Bouyer NI GP 0.011 [RMCA]. DR Congo. 10, Uele, Paulis, 1959.10.20, [RMCA]. 1 $\delta^{\lambda}$, as above but VII.1958, leg. Dr M. Fontaine, NI GP 0.002 [RMCA]. $1 \hat{\partial}$, as above but 3.IV.1960, NI GP 0.004 [RMCA]. 1으, as above but 1.XII.1956. 1 으, as above but 30.VII.1959. 1우, as above but V-1957, NI GP 0.009 [RMCA]. 1 , , Eala X-1935, leg. J. Chesquière NI GP 0.010 [RMCA]. Congo. $1 \hat{\delta}$, Lefinie reservation bungalows near Mpo, 1964-01-10, leg. Endrody-Younga, [ISEAPAS]. 1ठð, Odzala Nat. Park., H: 400-500 m, 0²3'N, 1450’E, 29.01-03.03.1997, leg. Siniaev \& Murzin. GP No. 36.294 [MWM]. Equatorial Guinea. $1 \hat{\delta}$, Fernando Poo, 1940-1941 [NHMUK]. Angola. 1 $\sigma^{\lambda}$, Cuanza Sul Prov., rd. Quibala-Mussende, ca. $80 \mathrm{~km}$ E Quibala, $10^{\circ} 35^{\prime} 43.7^{\prime \prime} \mathrm{S} 15^{\circ} 38^{\prime} 38.7^{\prime \prime} \mathrm{E}, 1352 \mathrm{~m}, 2017-11-22$, leg. S. Naumann, E. Ott, H. Sulak [ISEAPAS].

Type locality. Gabon, Valley of the Ogooué River, Lambarene.

Distribution (Fig. 12). Cameroon, Equatorial Guinea, Gabon, Republic of the Congo, Democratic Republic of the Congo, Angola.

Remarks. M. haematoessa was described based on a single female specimen. Unfortunately, genitalia of holo- 


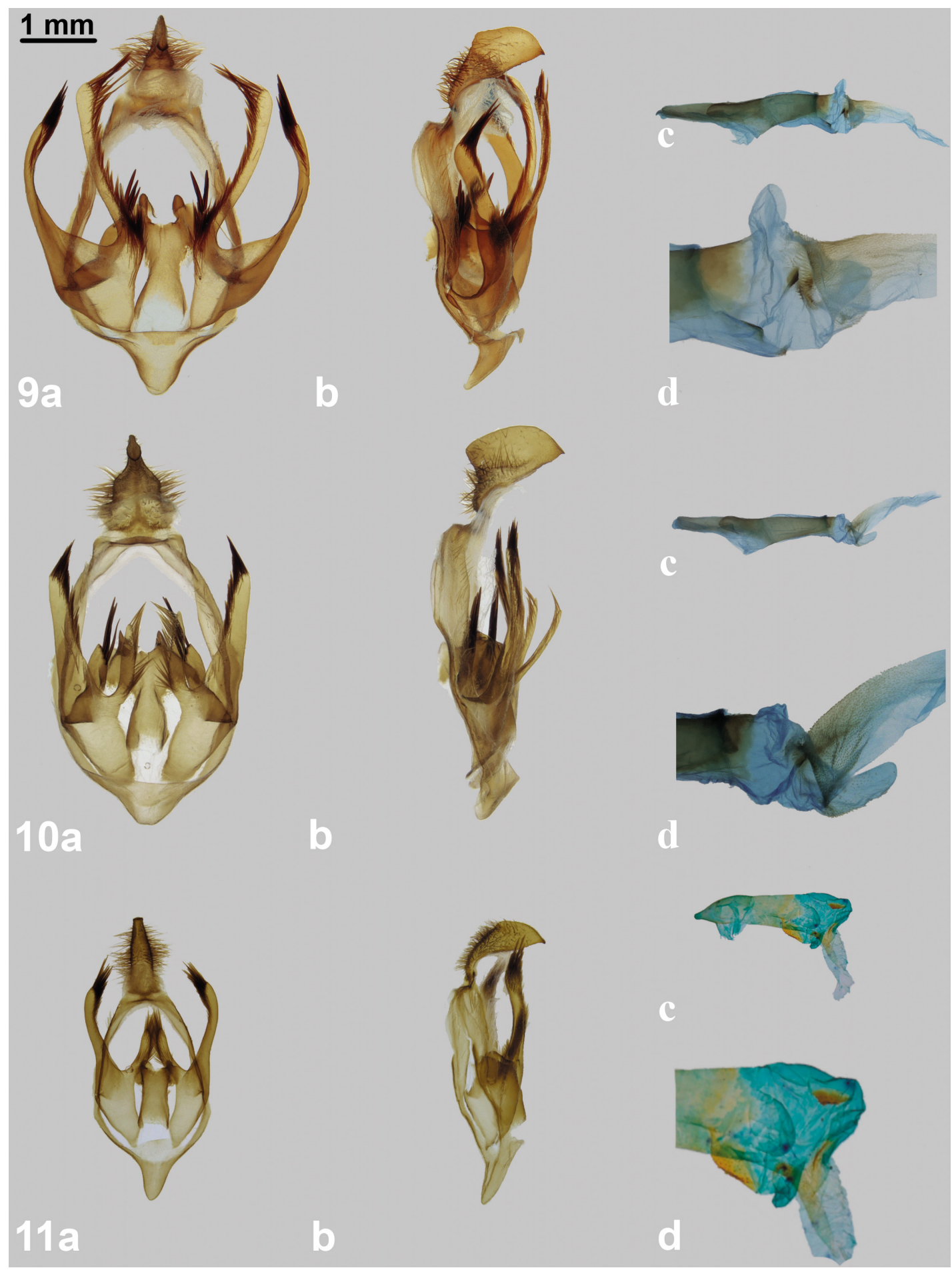

Figs 9-11. Male genitalia of Mecistorhabdia spp. 9 - M. haematoessa, GP 36.294 in MWM. 10 - M. burgessi, GP GP 36.295 in MWM. 11 - M. sulaki sp. n., GP 0.005 in RMCA. a - ventral view; b - lateral view; c - aedeagus; d - vesica magnified.

type specimen are destroyed so it is not possible to complete the analysis. Detection of a new taxon with unknown females sympatrically distributed with haematoessa raised the question about the real identity of the sexes ascribed until now to already known taxa. Due to the overall similarity of all three Mecistorhabdia species, scarcity of females and significant difference in size between males and females it was not obvious if the female type of haematoessa should be associated with the male morphotypes proposed by Kiriakoff (1953) or with those of the newly discovered new taxon. The only reliable and convincing answer for this question was the analysis and comparison of molecular characters of both male morphotypes and the female holotype of M. haematoessa.

\section{Mecistorhabdia burgessi Kiriakoff, 1957, sp. rev.}

(Figs 3, 4, 10, 12, 13, 15)

Mecistorhabdia burgessi Kiriakoff, 1957: 96. 


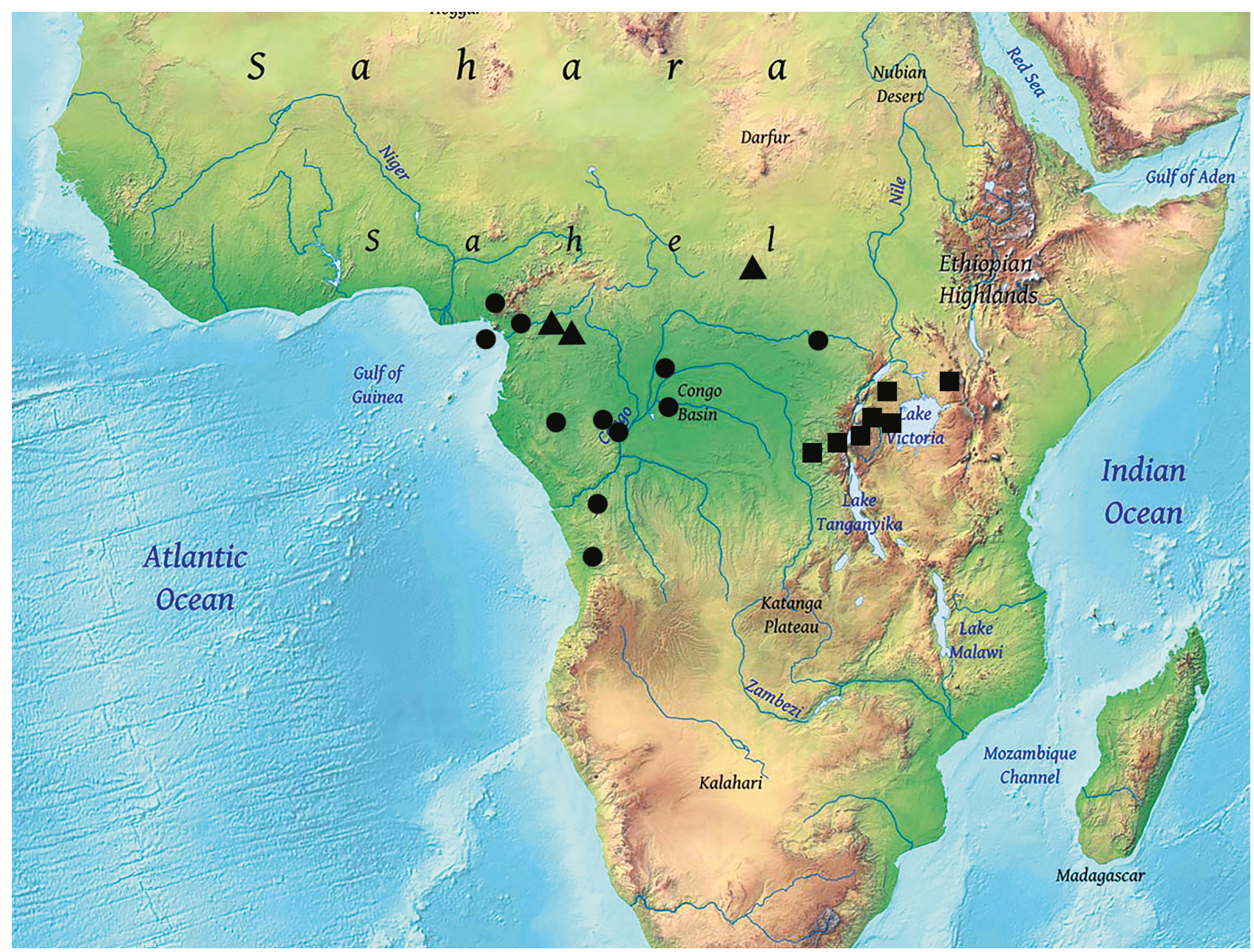

Fig. 12. Distribution of the species of the genus Mecistorhabdia.

- M. haematoessa;

- M. burgessi;

- M. sulaki.

Mecistorhabdia burgessi Kiriakoff, 1957: Przybyłowicz \& Kühne 2008: 150; Przybyłowicz 2009: 56.

Diagnosis. This species differs from others in external view of adult, which has a more intensive orange and darkgrey colouration on forewing and pale orange hindwing. Specimens of this species are frequently mixed together with $M$. haematoessa in collections of Lepidoptera. It differs from the latter taxon by smaller wingspan of male 28-30 mm compared to $30-35 \mathrm{~mm}$ in M. haematoessa. The structure of male genitalia should be used for safe identification, so in contrast to $M$. haematoessa saccular process of valvae is distinctly shorter than costal process and vesica has no distinct cornutus (only tiny sclerotizations). It should also be noted that the costal process of valvae is almost straight in comparison with those of $M$. haematoessa. We removed the taxon burgessi from the synonymy of $M$. haematoessa in view of the distinct differences in structures of male genitalia.

Male (Figs 3, 4). Antenna bipectinate, bright yellow. Head and patagia dark brown, tegula, thorax covered by dirty orange and brown elongate scales. Abdomen dorsally dirty orange, ventrally pale brown. Wingspan 28-30 mm. Forewing dirty orange dark-grey, with intense orange costal margin and blurs of orange scales on postbasal, discal, postdiscal areas. Marginal edge of forewing mainly dirty orange. Hindwing pale-orange with grey scales on marginal edge.

Female. Unknown.

Male genitalia (Fig. 10). Uncus of coracoid shape, extended in medial part; dorsally and laterally covered by elongate scales. Tegumen ribbon-shaped. Valvae symmetrical, divided into two elongated and slightly curved processes: saccular process, which is distinctly shorter than costal process, slightly curved, covered by setae abdominally; costal process narrows towards top, dorsal edge and tip covered by elongate setae. At the base valvae bear a basal appendage, which is almost half the size of costal process, curved dorsally and tip well covered with sclerotized elongate setae. Juxta well developed, almost Xshaped. Saccus rounded at top. Aedeagus tubular, narrows towards top. Vesica divided in to two lobes - elongated abdomen with field of tiny scrobinations at the base and laterally, which is much shorter and without cornuti.

Type material examined. Holotype: $\widehat{\partial}$, S.W. Uganda, Kigezi Distr., Impenetrable Forest, Kanungu, 4500 ft., May 1952 (J.A. Burgess) [NHMUK].

Other material examined. Uganda. $1 \hat{\jmath}$, Kalinzu Forest, [..]65.01.7-10, leg. J. Scheven, [ZSM]; 1ठ, Kibale Forest NP., Makarere Univ. Field Station, 1590 m, $0^{\circ} 34^{\prime} 11^{\prime \prime N} 30^{\circ} 22^{\prime} 29^{\prime \prime} \mathrm{E}$, 


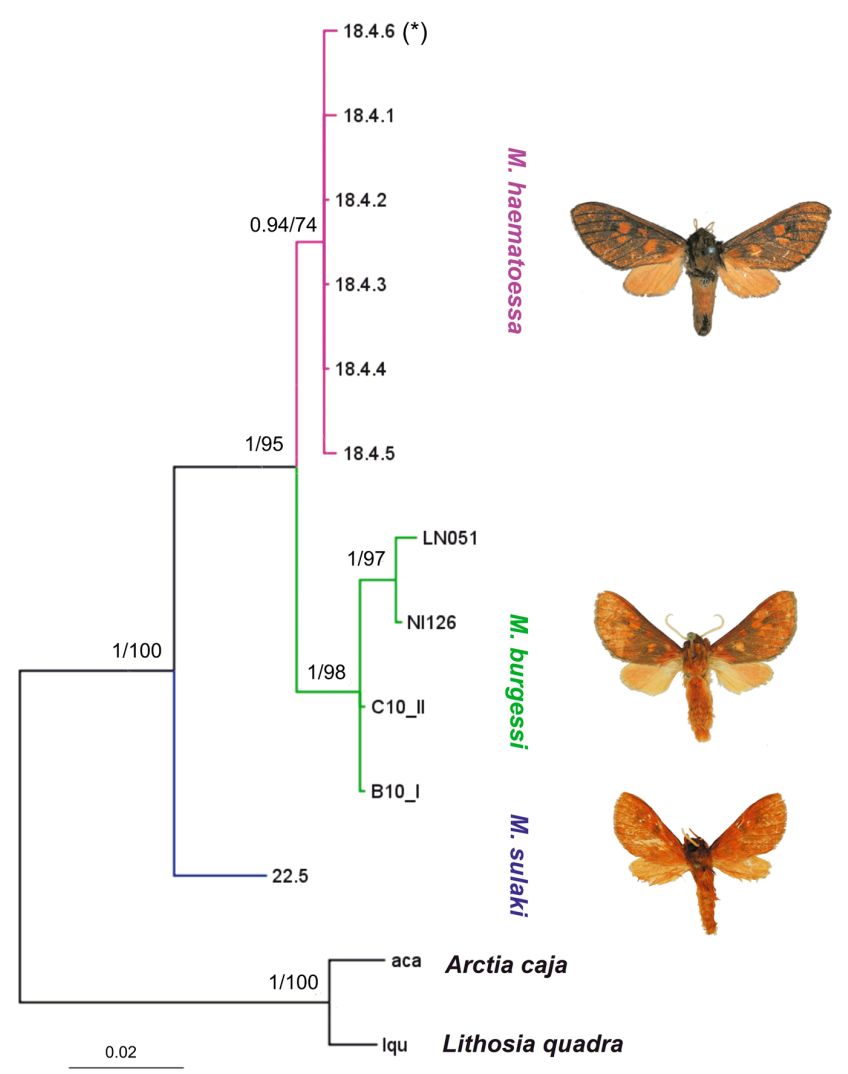

Fig. 13. Bayesian phylogenetic tree of the genus Mecistorhabdia based on sequences of mitochondrial cytochrome $\mathrm{c}$ oxidase subunit I (COI). The two values on each branch are Bayesian posterior probability (PP) and maximum likelihood bootstrap support (BS) as PP/BS (only branches with support values above $50 \%$ ). (*) indicates the female holotype of $M$. haematoessa.

2014-10.21, leg. Ł. Przybyłowicz, [ISEAPAS]; 1ð, Kibale Forest NP., Makarere Univ. Field Station, $1550 \mathrm{~m}, 0^{\circ} 33^{\prime} 53^{\prime \prime} \mathrm{N}$ $30^{\circ} 21^{\prime} 23^{\prime \prime}$ E, 2014.10.20, leg. Ł. Przybyłowicz, [ISEAPAS]; $2{ }^{\jmath}$ as above but 2014.10.19. $1 \delta^{\dagger}$ Western region, Prov. Fort Portal, Kibale National Park. N $0^{\circ} .086^{\prime}$ E $30^{\circ} 17.623^{\prime}$ 6.-7.VII.2011, 1520 m., leg. H. Sulak, GP No. 26.851 [MWM]. $1 \delta^{\Uparrow}$ Western region, Prov. Fort Portal, Lake Nkuruba, N $0^{\circ} 31.100^{\prime} \mathrm{E} 30^{\circ} 18.146^{\prime}$ 1.-6.VII.2011, 1530 m., leg. H. Sulak, GP No. 34.264 [MWM]. Kenya. $1 \hat{\jmath}$, Mt. Elgon, Juni 1951, leg. T.H. Jackson, NI GP 0.001 [RMCA]. Tanzania. 2ð, Bukoba, [..]64.09-10., leg. J. Scheven, [ZSM]. DR Congo. $1 \partial^{\lambda}$, Kivu, Nyamunyunye (Mulungu) 13.II.1956, leg. J. Hecq, NI GP 0.003 [RMCA]. 1 ${ }^{\lambda}$, Kashuscha [N ad Bukavu???], coll. Le Moult [RBINS]. 1ठ, Salonga NP, N 20¹8'55", S 02 $45^{\prime} 22^{\prime \prime}, 2016.03$, leg. Muller, Kravchenko, Traore [ZSM].

Type locality. SW Uganda, Kanungu.

Distribution (Fig. 12). Democratic Republic of the Congo, Uganda, Kenya, Tanzania.

\section{Mecistorhabdia sulaki sp. $\mathrm{n}$.}

(Figs 5, 6, 11, 12, 13, 15)

\section{ZooBank taxon LSID:}

4DA10EF3-74D9-42B6-BF5A-80B506BD1D0A

Diagnosis. This species differs from others in its smaller size - wingspan $27 \mathrm{~mm}$, colouration of the forewing, which

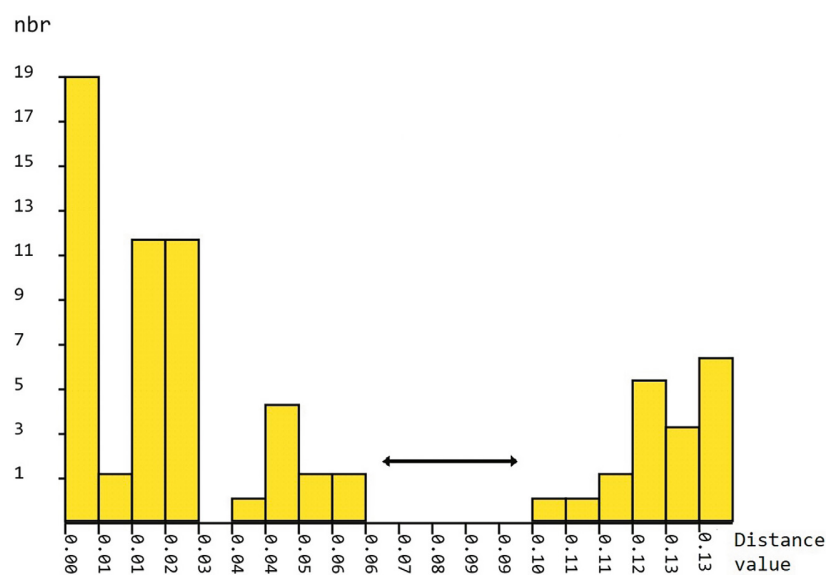

Fig. 14. Barcode gap analysis of $\mathrm{CO}$ sequences performed using ABGD. Histogram shows the distribution of pairwise genetic distances (K80) between each pair of specimens. The horizontal axis shows the pairwise K80-distance, and the vertical axis the number of pairwise sequence comparisons. The arrow indicates the gap that distinguishes between intraspecific (left) and interspecific (right) distances for the $\mathrm{COI}$ region.

is distinctly brighter. The structure of male genitalia should be used for safe identification, because in contrast to $M$. haematoessa and M. burgessi the valvae have no basal appendage, basal part of the aedeagus is distinctly narrow, vesica has one area of tiny sclerotizations and two flattened round cornuti.

Male (Figs 5, 6). Antenna bipectinate, bright yellow. Head, patagia and thorax covered by dirty orange elongate scales. Abdomen dorsally orange, with elongate pale-yellow scales on tip. Wingspan 23-27 mm. Forewing bright orange yellow with deep orange costal margin and blurs of grey scales on postbasal, discal and postdiscal areas. Marginal edge of forewing mainly yellow. Hindwing paleyellow.

Female. Unknown.

Male genitalia (Fig. 11). Uncus apparently extends to middle part and bears a small sharpened appendage on the tip; dorsally and laterally covered by elongate scales. Tegumen ribbon-shaped. Valvae symmetrical, divided in two elongated and slightly curved processes: costal process long, slightly extended, rounded and bears setae on distal part; saccular process half the length of costal process, with slightly rounded tip, ventrally covered by elongate setae. Juxta well developed and elongated. Saccus with rounded top. Aedeagus tubular, narrows and slightly curved basal part. Vesica divided in two lobes - elongate dorsal with area of minute sclerotizations and abdominal with two flat rounded cornutti.

Type material. Holotype $\widehat{\partial}$, Africa, Central African Republic, Bangui N 4²0 / E 18³2, 20 Sept. 2000, 350 m, leg. local collector, ex coll. Th. Greifenstein, Thomas Witt Stiftung, GP No. 26.861 [MWM]. Paratypes (4 $\overbrace{}^{\lambda}$ ). $1 \delta^{\lambda}$, Cameroun: Nyazanga, 5/809-1992, Th. Bouyer, NI GP 0.005 [RMCA]; $2 \hat{\jmath}$, Africa, Central African Republic, Bangui, N $4^{\circ} 20$ / E 18 ${ }^{\circ} 32,20$ Sept. 2000, 350 m. leg. local collector, ex. coll. Th. Greifenstein, Thomas Witt Stiftung [MWM]; 1ð, Cameroun, Ebogo, 04.IV-16.IV.2013, Piotr Kowalski leg. [ISEAPAS]. 


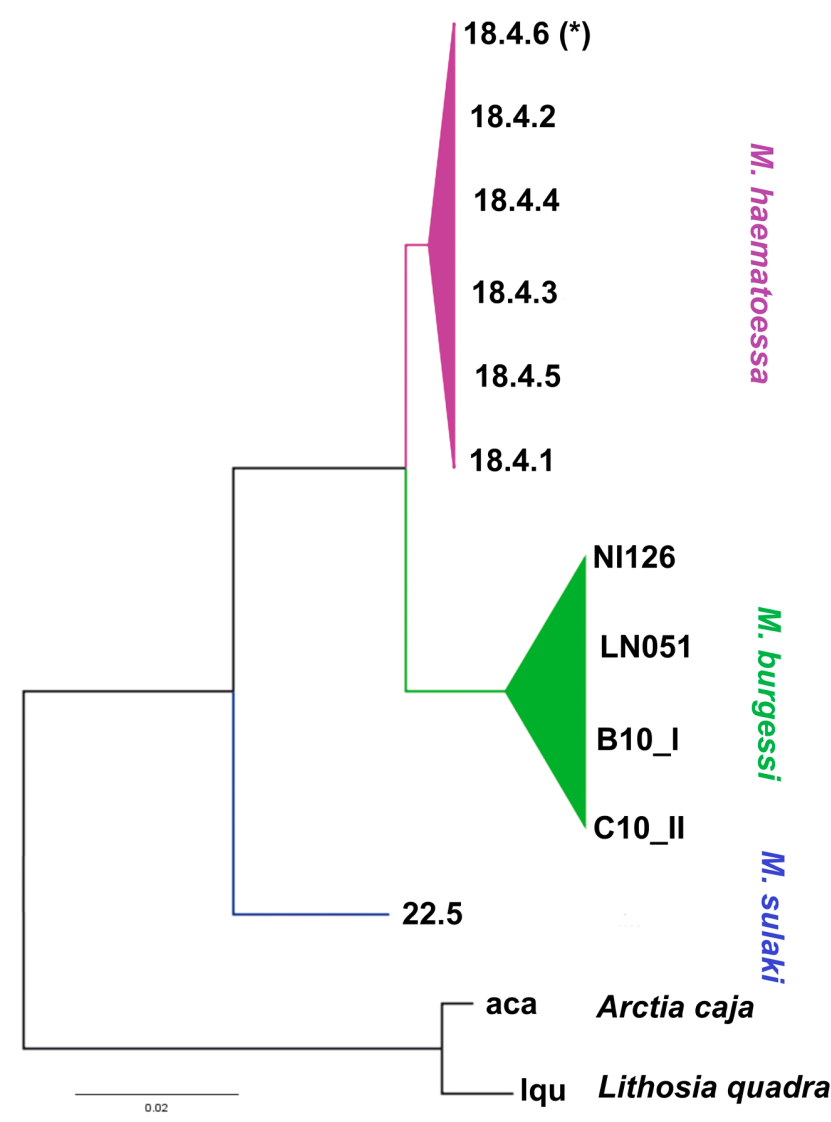

Fig. 15. Neighbour-joining phylogenetic tree showing the groups (hypothetical species) revealed by the ABGD analysis. ( ${ }^{*}$ ) indicates the female holotype of $M$. haematoessa.

Type locality. Central African Republic, Bangui, $4^{\circ} 20^{\prime} \mathrm{N}$, $18^{\circ} 32^{\prime} \mathrm{E}, 350 \mathrm{~m}$.

Etymology. We are pleased to name this new species in honour of Harald Sulak, collector and collection manager of the Museum Witt.

Distribution (Fig. 12). Cameroon, Central African Republic.

Remarks. Specimens of $M$. sulaki sp. n. were collected at two localities: Central African Republic and Cameroon, in the last it flies at the same time as M. haematoessa.

\section{Key to the species of the genus Mecistorhabdia based on male genitalia}

1 Saccular process of valvae longer or the same length as costal process ......................................................... haematoess

- Saccular process of valvae shorter than costal process ........ 2

2 Valvae with basal appendage; aedeagus without distinct cornutus, bearing only an area of tiny sclerotizations .... burgessi

- Valvae without basal appendage; aedeagus with two distinct cornuti and an additional field of tiny sclerotizations.

sulaki sp. $\mathrm{n}$

\section{Results of molecular studies}

There were no indels and stop codons in the $613 \mathrm{bp}$ of COI. The MrModeltest indicated that the SYM + G (gamma distribution shape parameter $\mathrm{G}=0.7231$ ) as the best model of DNA substitution. The phylogenetic trees calculated using different methods had identical topologies, so only the Bayesian tree is shown (Fig. 13). The Bayesian poste- rior probability values for the nodes were generally higher than the bootstrap values. In the genus Mecistorhabdia species were clearly separated and formed a monophyletic group. The phylogenetic analysis divided the genus into three lineages in which Mecistorhabdia sulaki was a sister species to M. haematoessa + M. burgessi.

The K2P distances of the COI gene (barcoding region) between different Mecistorhabdia specimens ranged from 0 to $6 \%$ (Table 2). The maximum distance between the specimens of $M$. haematoessa was $0.3 \%$. The oldest representative of $M$. haematoessa (the female holotype, specimen No. 18.4.6) was similar to the rest of the specimens of this species. The genetic divergence values between specimens of $M$. burgessi ranged from 0 to $0.99 \%$. Average distance between $M$. burgessi and $M$. sulaki included in the analysis was $6 \%$.

The ABGD method revealed gap between intra- and interspecific distance variation in the barcoding (Fig. 14). Hence, ABGD tree also clustered the COI sequences into three Mecistorhabdia groups (putative species) (Fig. 15), which are congruent with the phylogenetic tree (Fig. 13).

\section{DISCUSSION}

Mecistorhabdia is one of the smallest genera of Syntomini. However, the thorough investigation based on both morphological and molecular characters revealed hidden diversity within until now a monotypic genus. The previous study of the single types of $M$. haematoessa (female) and $M$. burgessi (male) led to the incorrect assumption that they represent a single taxon (Przybyłowicz \& Kühne, 2008). This was due to the uniformity of both taxa in terms of pattern, colouration and male genitalia.

It is likely that careful reexamination of material (both existing in collections and new) of several other monotypic genera of Arctiinae from a wide area, including a morphogenetic analysis, would reveal the existence of further undescribed taxa. Such discoveries are already reported for Cacoethes Hübner, 1816 (de Freina, 2014) and Neophemula Kiriakoff, 1957 (Ochse, 2017).

Our study once again proves that old museum material can be used in molecular procedures to solve long-lasting taxonomic problems such as matching opposite sexes, detecting the molecular characters of unique types or ascribing incomplete types to particular taxa (Strutzenberger et al., 2012; Prosser et al., 2016). This last aspect is especially important when the genitalia are damaged due to mechanical (crushing, tearing) or biological (fungi, pests) factors. In such cases, COI sequences can be extracted from even small fragments of highly degraded DNA and provide crucial information on the taxonomic identity of the specimen analyzed.

Based on the above taxonomic treatment further studies can now be carried out on the genus Mecistorhabdia. In terms of morphology future studies should concentrate on collecting the so far undiscovered females of $M$. burgessi and $M$. sulaki. This fresh material will help in defining the distributions of the sympatric M. haematoessa and $M$. sulaki. The question of the intraspecific genetic variation of each species should be studied using freshly collected 
Table 2. Inter- and intraspecific K2P distances of COI sequences in Mecistorhabdia. $\left(^{*}\right)$ indicates the female holotype of M. haematoessa.

\begin{tabular}{|c|c|c|c|c|c|c|c|c|c|c|c|}
\hline COI & 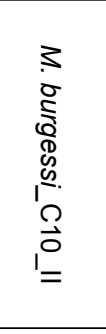 & 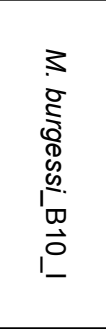 & 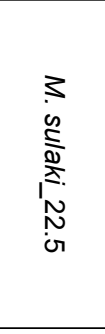 & 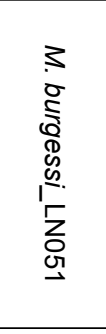 & 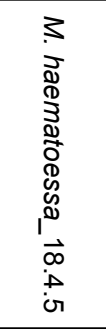 & 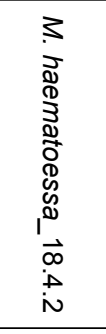 & 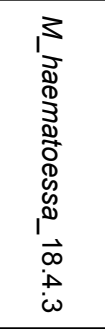 & 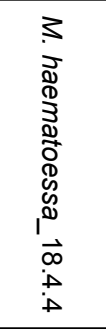 & 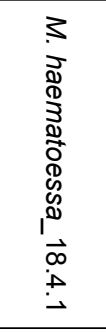 & 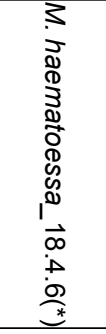 & 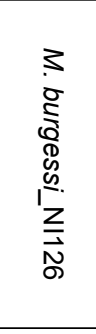 \\
\hline M. burgessi_C10_II & 0.0000 & & & & & & & & & & \\
\hline M. burgessi_B10_I & 0.0000 & 0.0000 & & & & & & & & & \\
\hline M. sulaki_22.5 & 0.0528 & 0.0528 & 0.0000 & & & & & & & & \\
\hline M. burgessi_LN051 & 0.0099 & 0.0099 & 0.0634 & 0.0000 & & & & & & & \\
\hline M. haematoessa_18.4.5 & 0.0183 & 0.0183 & 0.0474 & 0.0284 & 0.0000 & & & & & & \\
\hline M. haematoessa_18.4.2 & 0.0166 & 0.0166 & 0.0457 & 0.0267 & 0.0016 & 0.0000 & & & & & \\
\hline M_haematoessa_18.4.3 & 0.0166 & 0.0166 & 0.0457 & 0.0267 & 0.0016 & 0.0000 & 0.0000 & & & & \\
\hline M. haematoessa_18.4.4 & 0.0166 & 0.0166 & 0.0457 & 0.0267 & 0.0016 & 0.0000 & 0.0000 & 0.0000 & & & \\
\hline M. haematoessa_18.4.1 & 0.0182 & 0.0182 & 0.0474 & 0.0283 & 0.0033 & 0.0016 & 0.0016 & 0.0016 & 0.0000 & & \\
\hline M. haematoessa_18.4.6(*) & 0.0175 & 0.0175 & 0.0372 & 0.0281 & 0.0034 & 0.0017 & 0.0017 & 0.0017 & 0.0034 & 0.0000 & \\
\hline M. burgessi_NI126 & 0.0066 & 0.0066 & 0.0598 & 0.0033 & 0.0250 & 0.0233 & 0.0233 & 0.0233 & 0.0250 & 0.0245 & 0.0000 \\
\hline
\end{tabular}

specimens. M. burgessi seems to be the typical representative of an East African fauna with the western border of its range in Ruwenzori Mountains. However, this hypothesis should be confirmed by extensive collecting in the eastern part of the Congo basin.

ACKNOWLEDGEMENTS. We are very grateful to S. Hanot (RMCA), T.J. Witt (MWM) and A. Hausmann (ZSM) for giving us access to their collections of Lepidoptera. We appreciate the help of H. Sulak (MWM) in studying Arctiinae collections and his enthusiasm and interest in locating and collecting specimens of Thyretini during his research expeditions in Africa. We also thank J. Sternalski (ISEAPAS) for dissections, preparation slides of genitalia and photographing the parts of specimens of Mecistorhabdia. We are very grateful for the improvements suggested by the anonymous reviewers. We thank P. Kowalski (Warszawa) and S. Naumann (Berlin) for donating specimens of Mecistorhabdia to ISEAPAS.

\section{REFERENCES}

De Freina J.J. 2014: Über zwei Syntomini-Arten aus der Kapregion, Südafrika: Cacoethes polidamon (Cramer, 1779) comb. rev. und Cacoethes fulvatrum sp. n. (Lepidoptera: Erebidae, Arctiinae, Syntomini). — Entomol. Z. (Schwanfeld) 124: 3540.

Durante A. \& Potenza L. 2014: Novitates from Gabon (Erebidae, Arctiinae, Syntomini, Thyretina). - Lambillionea 64: 260-263.

Durante A. \& Zangrilli M. 2016: Review of subgenus Daphaenisca Kiriakoff, 1953 (Lepidoptera: Erebidae: Arctiinae: Synthomini: Thyretina), with identification keys, and description of three new species. - Zootaxa 4117: 151-171.

Folmer O., Black M., Hoen W., Lutz R. \& VRijenhoek R. 1994: DNA primers for amplification of mitochondrial cytochrome $\mathrm{c}$ oxidase subunit I from diverse metazoan invertebrates. - Mol. Mar. Biol. Biotechnol. 3: 294-299.

Holland W.J. 1893: Descriptions of new species and genera of West African Lepidoptera. - Psyche 6: 393-400.

JACOBSON N.J. \& Weller S.J. 2002: A Cladistic Study of the Arctiidae (Lepidoptera) by Using Characters of Immatures and Adults. Thomas Say Publications in Entomology: Monographs. Entomological Society of America, Lanham, MD, 98 pp.
KIRIAKOFF S. 1949: Over de phylogenie van de Thyretidae fam. nov. (Lepidoptera). - Natuurw. Tijdschr. 31: 3-10.

KiRIAKoff S. 1953: Les Thyretidae du Musée Royal du Congo Belge (Lepidoptera: Notodontoidea). - Ann. Mus. R. Congo Belge (Tervuren) (Sér. 8, Sci. Zool.) 8(26): 1-91.

KIRIAKOFF S. 1957: New Thyretidae (Lepidoptera Notodontoidea). - Tijdschr. Entomol. 100: 95-114.

KLots A. 1970: Lepidoptera. In Tuxen S.L. (ed.): Taxonomist's Glossary of Genitalia in Insects. Munksgaard, Copenhagen, pp. 115-130.

Kumar S., Stecher G., Li M., Knyaz C. \& Tamura K. 2018: MEGA X: Molecular Evolutionary Genetics Analysis across computing platforms. - Mol. Biol. Evol. 35: 1547-1549.

Nguyen L.T., Schmidt H.A., von Haeseler A. \& Minh B.Q. 2015: IQ-TREE: a fast and effective stochastic algorithm for estimating maximum-likelihood phylogenies. - Mol. Biol. Evol. 32: 268-274.

Nylander J.A.A. 2004: MrModeltest V.2. Program distributed by the author. Evolutionary Biology Centre, Uppsala University. URL: https://github.com/nylander/MrModeltest2/releases

OChSE M. 2017: Arctiinae der Subtribus Thyretina in der westafrikanischen Regenwaldregion (Erebidae). - Nachr. Entomol. Ver. Apollo (N.F.) 38: 1-22.

Prosser S.W., de WaArd J.R., Miller S.E. \& Hebert P.D. 2016: DNA barcodes from century-old type specimens using nextgeneration sequencing. - Mol. Ecol. Resour. 16: 487-497.

PrZYBYŁowicz Ł. 2009: Thyretini of Africa. An Illustrated Catalogue of the Thyretini (Lepidoptera, Arctiidae: Syntominae) of the Afrotropical Region. Entomonograph Series 16. Apollo Books, Stenstrup, 170 pp.

PrzYBYŁowicz Ł. \& KüHNe L. 2008: Subfamily Syntominae (Noctuoidea, Arctiidae). In Kühne L. (ed.): Butterflies and Moth Diversity of the Kakamega Forest (Kenya). Brandenburgische University, Potsdam, pp. 150-156.

Przybyłowicz Ł., Lees D.C., ZenKer M.M. \& Wahlberg N. 2019: Molecular systematics of the arctiine tribe Syntomini (Lepidoptera, Erebidae). — Syst. Entomol. 44: 624-637.

Puillandre N., Lambert A., Brouillet S. \& Achaz G. 2012: ABGD, Automatic Barcode Gap Discovery for primary species delimination. - Mol. Ecol. 21: 1864-1877.

Rambaut A. \& Drummond A.J. 2012: FigTree: Tree Figure Drawing Tool, v1.4.2. Institute of Evolutionary Biology, University of Edinburgh. URL: http://tree.bio.ed.ac.uk/software/figtree/ 
Rambaut A., Drummond A.J., Xie D., Baele G. \& Suchard M.A. 2018: Posterior summarization in Bayesian phylogenetic using Tracer 1.7. - Syst. Biol. 67: 901-904.

RonQuist F. \& HUELSENBECK J.P. 2003: MRBAYES 3: Bayesian phylogenetic inference under mixed models. - Bioinformatics 19: $1572-1574$.

Strutzenberger P., Brehm G. \& Fiedler K. 2012: DNA barcode sequencing from old type specimens as a tool in taxonomy: a case study in the diverse genus Eois (Lepidoptera: Geometridae). - PLoS ONE 7: e49710, 7 pp.
Zahiri R., Kitching I.J., Lafontaine J.D., Mutanen M., Kaila L., Holloway J.D. \& Wahlberg N. 2011: A new molecular phylogeny offers hope for a stable family-level classification of the Noctuoidea (Lepidoptera). — Zool. Scr. 40: 158-173.

Zeale M.R., Butuin R.K., Barker G.L., Lees D.C. \& Jones G. 2011: Taxon-specific PCR for DNA barcoding arthropod prey in bat faeces. - Mol. Ecol. Resour. 11: 236-244.

Received November 2, 2019; revised and accepted January 31, 2020 Published online April 8, 2020 